\title{
Efficacy of Er, Cr Laser incision Corticotomy in Rapid Maxillary Canine Retraction: A Split-Mouth Randomized Clinical Trial
}

\author{
Majid Mahmoudzadeh ${ }^{1}$, Banafshe Poormoradi², Sara Alijani ${ }^{3}$, Maryam Farhadian ${ }^{4}$, Azadeh Kazemisaleh ${ }^{5 *}$ \\ 'Department of Orthodontics, Faculty of Dentistry, Hamadan University of Medical Sciences, Hamadan, Iran \\ ${ }^{2}$ Assistant Professor, Laser Research Center, Department of Periodontology, School of Dentistry, Hamadan University of \\ Medical Sciences, Hamadan, Iran \\ ${ }^{3}$ Orthodontic Department, Dental Faculty, Hamadan University of Medical Sciences, Hamadan, Iran \\ ${ }^{4}$ Assistant Professor of Biostatistics, Modeling of Noncommunicable Diseases Research Center, Department of Biostatistics, \\ School of Public Health, Hamadan University of Medical Sciences, Hamadan, Iran \\ ${ }^{5}$ Postgraduate Student, Department of Orthodontics, School of Dentistry, Hamadan University of Medical Sciences, Hamadan, \\ Iran
}

\section{*Correspondence to Azadeh Kazemisaleh Tel: +98937-880-5023; Email: \\ azadeh.kazemisaleh@gmail. com \\ Published online October 3,2020}

\begin{abstract}
Introduction: This study sought to evaluate the efficacy of lasercision corticotomy for the acceleration of canine movement. Our secondary objectives were assessing the canine rotation, the rate of anchorage control, the level of pain, and the gingival index (Gl).

Methods: Twelve orthodontic patients ( 9 females and 3 males) referring to the School of Dentistry and one dental clinic from May 2019 to September 2019 participated in this split-mouth randomized clinical trial. The allocation of the test and control sides was performed by flipping a coin. The mean age of patients was $18.91 \pm 3.87$ years (range 15-30 years). The treatment plan included maxillary first premolar extraction. Following the initial leveling and alignment phase, an initial impression was made. Corticotomy was carried out with the erbium, chromium-doped yttrium scandium gallium garnet (Er, Cr: YSGG) laser ( $3.5 \mathrm{~W}, 30 \mathrm{~Hz}, 40 \%$ air, $80 \%$ water) in one maxillary quadrant (the laser side). Canine retraction was immediately initiated following surgery using nickel-titanium closed-coil springs with 150 $\mathrm{g}$ force. The impression was repeated 1 month after the onset of retraction. The casts were scanned, and the distance between the canine cusp tip and the rugae line was measured to quantify the amount of anteroposterior canine movement. The molar anchorage control was also evaluated by measuring the distance between the mesial contact of the permanent first molar and the rugae line. Gingival health was evaluated using the GI. The modified McGill pain questionnaire was used to assess the level of patients' pain.

Results: Lasercision corticotomy accelerated canine retraction with no adverse effect on gingival health. Anchorage loss in the posterior teeth and pain scores were not significantly different between the control and laser sides.

Conclusion: Laser corticotomy can effectively accelerate canine retraction with no complications or discomfort for the patients.
\end{abstract}

Keywords: Lasers; Orthodontic tooth movement; Acceleration; Minimally invasive surgical procedures.

\section{Introduction}

Fixed orthodontic treatment takes 2 to 3 years. ${ }^{1-3}$ In fixed orthodontic treatment, canine retraction is a key timeconsuming process in patients with extracted premolars. The rate of the canine retraction procedure by the conventional techniques is 0.5 to $1 \mathrm{~mm}$ per month. Thus, canine retraction alone takes 5 to 9 months ${ }^{4}$ and increases the risk of caries $^{5,6}$ and external root resorption ${ }^{7,8}$ and decreases patients' cooperation which is a matter of concern. ${ }^{9}$ Therefore, efforts to accelerate the speed of tooth movement and shorten the treatment course can be quite useful.

To date, various strategies have been proposed for tooth movement acceleration, including low-level laser therapy, ${ }^{10,11}$ the use of electromagnetic pulses ${ }^{12}$ and electric currents, ${ }^{9}$ corticotomy, ${ }^{13,14}$ bone distraction, ${ }^{15-17}$ and mechanical vibration. ${ }^{18}$

In 2012, Long et al conducted a systematic review to evaluate the efficacy of five interventions including laser, corticotomy, electric current, use of electromagnetic pulses, and periodontal or dentoalveolar distraction. They showed that among the tested treatments, corticotomy

Please cite this article as follows: Mahmoudzadeh M, Poormoradi B, Alijani S, Farhadian M, Kazemisaleh A. Efficacy of Er,Cr laser incision corticotomy in rapid maxillary canine retraction: a split-mouth randomized clinical trial. J Lasers Med Sci. 2020;11(4):442-449. doi:10.34172/jlms.2020.69. 
was safe and effective for tooth movement acceleration, while low-level laser therapy was not effective for this purpose. None of the reviewed studies demonstrated the optimal efficacy of electric currents or electromagnetic pulses to accelerate tooth movement. Also, there was no convincing evidence regarding the efficacy of periodontal or dentoalveolar distraction. ${ }^{19}$

Yi et al, examined the efficacy of adjunct interventions for the acceleration of tooth movement and stated that based on low-quality evidence, low-level laser therapy (5 and $8 \mathrm{~J} / \mathrm{cm}^{2}$ ) and corticotomy would be effective in the acceleration of tooth movement in the short term. They called for more high-quality studies to determine the optimal protocols for this purpose. ${ }^{9}$

Orthodontic tooth movement occurs as a result of the mechanical stimulus that causes alveolar bone and periodontal ligament remodeling. ${ }^{20}$ The force applied to the teeth alters the blood flow and induces the release of various pro-inflammatory mediators. Neurotransmitters and the metabolites of the arachidonic acid change the environment around the periodontal ligament and as a result, bone remodeling occurs. ${ }^{21,22}$

Surgery is an effective clinical approach for patients to whom the duration of treatment is important. Various surgical techniques have been employed to accelerate tooth movement, including interdental alveolar surgery, osteotomy, corticotomy, and piezosurgery. ${ }^{14,17,23-27}$

Corticotomy is a surgical procedure commonly performed to decrease cortical bone resistance and accelerate tooth movement. In this technique, only the cortical bone is cut without invading the cancellous bone. $^{28}$ Corticotomy was first used by Köle ${ }^{28}$ in orthodontics in 1959 and after him, several researchers used this technique. ${ }^{29,30}$ In 1981, Frost stated that trauma to the bone would cause bone remodeling. A subsequent decrease in bone density and a transient local increase in bone metabolism would lead to a regional acceleratory phenomenon (RAP), resulting in faster orthodontic movements. ${ }^{31}$ According to a study by Hajj et al, orthodontic treatment was 2 times faster in patients undergoing corticotomy than in patients who did not undergo this procedure. ${ }^{32}$ Moreover, it has been stated that accelerated orthodontic tooth movement by corticotomy would decrease root resorption and periodontal problems due to orthodontic treatment. ${ }^{33}$

Wilcko et al were the first to introduce periodontally accelerated osteogenic orthodontics in 2000, which is an augmented corticotomy with an alveolar bone graft. They stated that this technique would increase the rate of tooth movement due to the enhanced thickness of bone and the consequent loss of tissue memory. ${ }^{34} \mathrm{~A}$ recent meta-analysis published in 2019 summarized the existing evidence on this topic and indicated that the outcome of augmented and non-augmented corticotomy was not significantly different. ${ }^{35}$

Although corticotomy has many benefits, it increases the morbidity compared with the conventional orthodontic treatment. ${ }^{34}$ Due to the invasive nature of corticotomy, some authors have suggested the use of flapless techniques such as the erbium (Er) laser. Laser irradiation on hard tissue increases the temperature of water and tissue fluids and ultimately leads to hard tissue ablation. ${ }^{36}$ Several studies have demonstrated that creating a hole by an Er, Cr laser results in optimal healing of the hard and soft tissues. ${ }^{37-39}$ The Erbium laser affects the cortical bone and leads to RAP without postsurgical complications. ${ }^{36}$ Several studies have shown significantly higher tooth movements with erbium laser corticotomy compared with conventional treatment. ${ }^{36,40,41}$

Laser surgery has advantages over the conventional treatment, such as no need for flap elevation, less invasive nature, no postoperative edema or pain, fast gingival healing without scarring, no trauma to the interdental papilla, and no gingival recession. ${ }^{36}$

The operating time and the postoperative discomfort would decrease when the corticotomy is limited to the alveolar bone buccal surface with/without a mucoperiosteal flap. Also, traumatization of lingual tissue can be prevented. ${ }^{42,43}$

Due to the lack of clinical trials in this field, this study sought to assess the effect of corticotomy with the erbium, chromium-doped yttrium scandium gallium garnet (Er, Cr: YSGG) laser on the canine retraction rate.

\section{Materials and Methods}

\section{Sample}

This randomized, split-mouth, clinical trial was accomplished within 4 months (May 2019 to September 2019) at the Department of Orthodontics, School of Dentistry, Hamadan University of Medical Sciences.

Eligible patients were recruited from the School of Dentistry and one orthodontic clinic in Hamadan city.

The minimum sample size was calculated to be 12 in each group according to a previous study ${ }^{40}$ assuming a two-sided 5\% significance level and a study power of $80 \%$, expected mean difference of 1 unit, and the standard deviation of 0.9 .

The inclusion criteria were as follows:

- Patients scheduled for orthodontic treatment of the maxilla, comprising of bilateral extraction of premolars with a maximum of a 2-month interval, followed by canine retraction

- $\quad$ The age range of 15 to 30 years

- Good oral hygiene (maximum plaque index of 30\%)

- Adequate attached gingival thickness (3 $\mathrm{mm}$ )

- Atraumatic tooth extraction

The exclusion criteria were as follows:

- Active periodontal disease that would affect the tooth movement due to poor bone quality

- $\quad$ Probing depth greater than $3 \mathrm{~mm}$

- History of previous orthodontic treatment

- Systemic diseases that could affect the bone 
structure or bone density, including osteoporosis, hyperparathyroidism or vitamin D deficiency

- Long-term intake of non-steroidal anti-inflammatory drugs, hormonal supplements or tricyclic antidepressants because they may interfere with bone metabolism.

Twelve patients were enrolled after obtaining their informed consent.

\section{Randomization}

In this study, we considered two treatment blocks for patients. In the first block, the right quadrant was considered as the control side while the left quadrant was considered as the laser side. In the second block, the left quadrant served as the control side and the right quadrant was considered as the laser side. The allocation of patients to the treatment blocks was performed by flipping a coin, which was done by someone not involved in the study.

\section{Intervention and Materials}

The MBT system with $0.022 \times 0.028$-inch slots was used for orthodontic patients. After completion of the leveling and alignment of the teeth, the probing depth was measured, and then the plaque index was measured according to the Loe plaque index. ${ }^{44}$ The maximum plaque index for the inclusion of patients in the study was $30 \%$ at the beginning of the retraction phase. Next, the width of the attached gingiva and the gingival index (GI) ${ }^{44}$ were measured. Periapical radiographs were obtained from the canine area to examine the root position and root proximity.

An alginate impression was made of the upper arch to serve as the primary record, and the plaster casts were poured.

Considering the random sampling method, corticotomy was performed using the Er, Cr:YSGG laser (Waterlase iPlus Biolase, CA, USA) with $3.5 \mathrm{~W}$ power, 30 $\mathrm{Hz}$ frequency, $\mathrm{H}^{\prime}$ mode and $40 \%$ air and $80 \%$ water using the MZ5 tip with $500 \mu$ diameter (Figure 1A). No dressing or suture was used after laser incision. Infiltration anesthesia was administered by the injection of lidocaine plus 1:80000 epinephrine (Daroupakhsh, Tehran, Iran). Next, using a hand-piece, a vertical incision was made in the buccal surface parallel to the mesial and distal root surfaces of the canine tooth $1 \mathrm{~mm}$ below the alveolar crest and extended to the mucogingival junction. It was 2 to 3 $\mathrm{mm}$ deep to reach the cancellous bone (Figure 1B). The depth of the incision was measured by a Williams probe (Hu-Friedy, IL, USA).

Immediately after the surgical procedure, a $0.016 \times$ 0.022 -inch stainless steel wire (3M Unitek, CA, USA) was inserted and then a 9-mm-long nickel-titanium closedcoil spring (Dentaurum, Ispringen, Germany) was used for canine retraction, which applied $150 \mathrm{~g}$ force to each side. The force was measured to be $150 \mathrm{~g}$ with a gauge, and the rest of the distance was closed with a ligature wire.
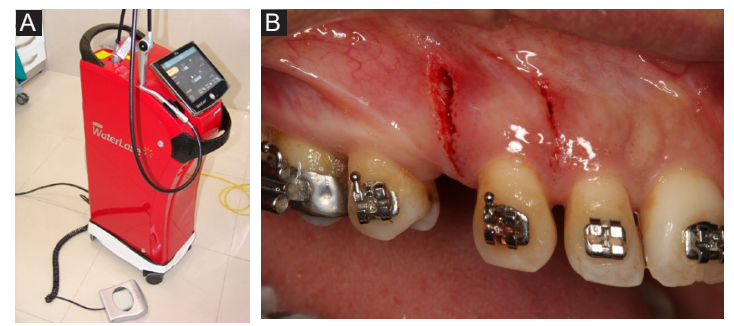

Figure 1. (A) Er,Cr:YSGG laser (Waterlase iPlus Biolase, USA). (B) A vertical incision was made in the buccal surface parallel to the mesial and distal root surfaces of the canine.

Because of the bactericidal effects of the laser, no antibiotics were administered and the patients had no pain or edema following laser surgery. ${ }^{36}$

One month after the onset of the retraction phase, the wires were removed, an alginate re-impression was made, and the plaster casts were poured. The casts before and after the retraction were scanned using a 3D scanner (MDS500 Dental Scanner, Maestro3D, Pisa, Italy). Finally, the width of the attached gingiva was measured.

The reference lines on the scans included the midpalatal raphe (MPR) and the rugae line. The rugae line was drawn from the midpoint of the third right rugae perpendicular to the midline (Figure 2, red line). Evidence shows that measurements made to evaluate tooth movement using the third rugae are as reliable as the measurements made by cephalometric superimposition. ${ }^{45}$

After the onset of the canine retraction, all patients received the modified McGill pain questionnaire along with a visual analog scale (VAS) and were asked to fill out the questionnaire and bring it back on the next appointment, which was scheduled 4 weeks later. The questionnaire included questions about the onset of pain, its description, locality, duration, intensity, triggers, pain reduction, and use of medications. Moreover, in order to make sure of the accuracy of patient responses to the questionnaire, the questions were asked through a phone
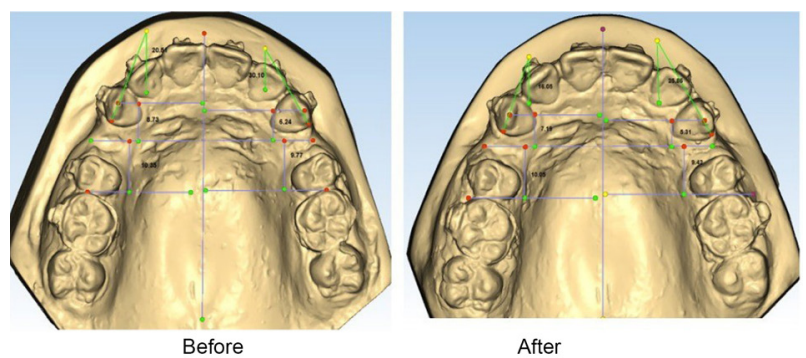

Figure 2. Casts before and after retraction were scanned using a 3D scanner. The reference lines were the mid-palatine raphe (MPR) and the rugae line ( $R L)$. DC, the distance between the cusp tip of the canine and the rugae line that indicates the anteroposterior canine movement; DM, the distance between the mesial contact point of the permanent first molar and the rugae line that indicates the molar movement; The angle between the median raphe and the line through the mesial and distal edges of the canine used to quantify the canine rotation. 
call 7 days after placing the springs in the mouth. Also, the patients were allowed to take only $325 \mathrm{mg}$ acetaminophen tablets if necessary (since acetaminophen does not interfere with orthodontic tooth movement).

The primary outcome was an increase in the canine movement rate, which was assessed by measuring the distance between the cusp tip of the canine and the rugae line (DC).

A line was also drawn from the mesial contact of the permanent first molar and the rugae line perpendicular to the midline, and the distance between them was used to measure the molar motion (DM). The median raphe was considered as the reference line. The angle formed between this line and another line passing from the mesial and distal surfaces of the canine tooth was measured and compared before and after the intervention to determine the degree of rotation of the canine tooth (angle index).

Our secondary outcomes were assessing the canine rotation, the rate of anchorage control, the level of pain, and the GI.

In this study, blinding the patients, clinicians, and the research director was not possible due to its specific design. But the assessor who analyzed the landmarks and measured the distances was blinded to the group allocation of the samples. Data were statistically analyzed by a statistician who was also blinded to the group allocation of the samples.

\section{Statistics}

The normal distribution of variables in different groups was evaluated using the Kolmogorov-Smirnov test. The distribution of variables was found to be normal in both groups. Therefore, the $t$ test was applied to compare the groups and the paired $t$ test was applied for intragroup comparisons $(\alpha=0.05)$.

\section{Results}

The mean age of the patients was $18.91 \pm 3.87$ years ( 15 to 30 years). Patient recruitment in the study began in May 2019 and ended in December 2019. The patient follow-up period was 30 days.

The $t$ test was applied for intergroup comparisons (Table 1). There was no significant difference between the control and laser groups at the baseline in the angle, DM or DC. One month after the treatment, the difference in DM and DC was not significant between the laser and control groups, but the difference was significant for the angle index (Figures 3 and 4).

However, the trend of change in DC ( $P$ value $<0.001$, mean difference $\pm \mathrm{SE}=1.16 \pm 0.25)$ and the angle index $(P$ value $=0.029$, mean difference $\pm \mathrm{SE}=-3.12 \pm 1.34)$ at 1 month compared with the baseline was significantly different between the control and laser groups. This difference was not significant for DM $(P$ value $=0$. 68, mean difference $\pm \mathrm{SE}=0.11 \pm 0.26$ ).

Intra-group changes were significant for the angle, DC and DM in both groups. Intra-group change in DC and angle size in the laser group was greater than that in the control group, whereas the change in DM was greater in the control group.

Of the 12 patients examined, only one patient reported pain in the laser side (VAS score: 2). The onset of pain was reported immediately after the wire insertion. The pain area was in the anterior teeth and the patient described it as compressive pain that lasted for less than one day. The patient did not take any medication for pain relief. There was no significant difference between the laser and control sides in the width of the attached gingiva neither before nor after the retraction.

According to Table 2, the mean difference between the control and laser groups at the baseline and 1 month after

Table 1. Intergroup and Intragroup Comparisons of the Mean DC, DM, and Angle Indices Between the Control and Laser Groups

\begin{tabular}{|c|c|c|c|c|c|}
\hline & \multirow{2}{*}{ Group } & Baseline & After 1 Month & \multirow{2}{*}{ Mean Difference \pm SE } & \multirow{2}{*}{$P$ Value* } \\
\hline & & Mean \pm SD & Mean \pm SD & & \\
\hline \multirow{4}{*}{ DC } & Control side & $10.67 \pm 2.64$ & $9.89 \pm 2.57$ & $0.79 \pm 0.12$ & $<0.001$ \\
\hline & Laser side & $11.25 \pm 3.56$ & $9.29 \pm 3.49$ & $1.95 \pm 0.22$ & $<0.001$ \\
\hline & Mean difference \pm SE & $-0.57 \pm 1.28$ & $0.59 \pm 1.25$ & $16.1 \pm 25.0$ & \\
\hline & $P$ value ** & 0.660 & 0.639 & $<001.0$ & \\
\hline \multirow{4}{*}{ DM } & Control side & $6.98 \pm 1.46$ & $6.30 \pm 1.62$ & $0.68 \pm 0.18$ & 0.003 \\
\hline & Laser side & $6.75 \pm 2.56$ & $6.18 \pm 2.49$ & $0.57 \pm 0.19$ & 0.012 \\
\hline & Mean difference \pm SE & $0.23 \pm 0.85$ & $0.12 \pm 0.86$ & $11.0 \pm 26.0$ & \\
\hline & $P$ value ** & 0.792 & 0.891 & 680.0 & \\
\hline \multirow{4}{*}{ Angle } & Control side & $29.98 \pm 4.26$ & $27.44 \pm 4.53$ & $2.54 \pm 0.71$ & 0.004 \\
\hline & Laser side & $27.02 \pm 7.78$ & $21.36 \pm 7.08$ & $5.66 \pm 1.13$ & $<0.001$ \\
\hline & Mean difference \pm SE & $2.96 \pm 2.56$ & $6.08 \pm 2.43$ & $-12.3 \pm 34$ & \\
\hline & $P$ value $* *$ & 0.261 & 0.020 & 029.0 & \\
\hline
\end{tabular}

* Paired $t$ test; ${ }^{* *} t$ test.

DC, canine movement rate; DM, molar movement rate.

Angle: The angle between the median raphe and the line passing through the mesial and distal canines. 


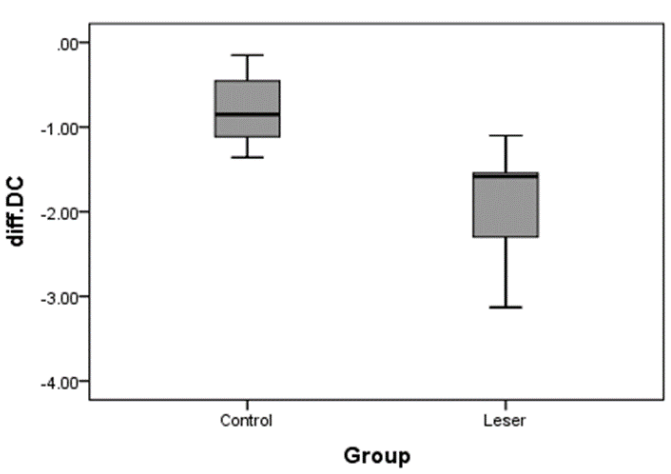

Figure 3. Box Plot of the Mean Difference of DC Between the Control and Laser Groups. There was a significant difference in the mean DC between the two groups.

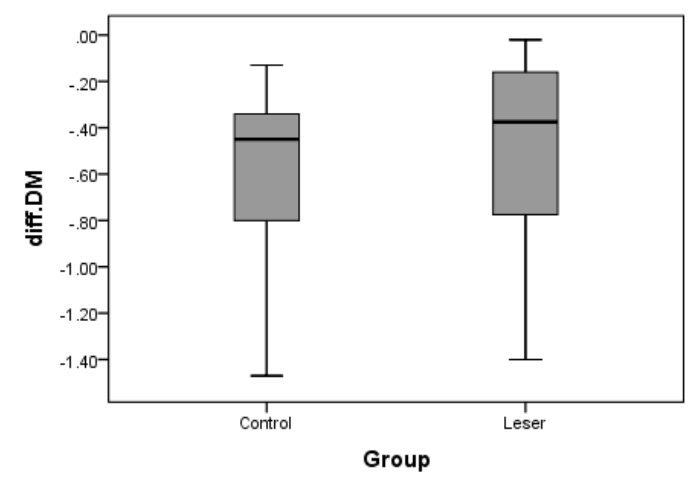

Figure 4. Box Plot of the Difference in the Mean DM Between the Control and Laser Groups. There was no significant difference in the mean DM between the two groups.

the intervention for the GI was not significant $(P$ value $=0$. 55 , mean difference $\pm \mathrm{SE}=0.061 \pm 0.05)$. In this trial, no harm was observed due to Er,Cr lasercision corticotomy.

\section{Discussion}

Due to the disadvantages of prolonged orthodontic treatment, this study assessed the effect of corticotomy on the speed of canine retraction after first premolar extraction. In other words, RAP was evaluated in teeth that underwent corticotomy. Also, because of the benefits of laser surgery over conventional treatments, such as not requiring a flap, less invasive nature, no postoperative edema or pain, rapid gingival healing without scarring, no trauma to the interdental papillae and no gingival recession, ${ }^{36}$ the Er,Cr:YSGG laser was used for corticotomy in this study.

The available studies on the acceleration of orthodontic treatment with lasercision corticotomy are mostly case reports or animal studies, ${ }^{3,34}$ and human studies on the efficacy of Er,Cr:YSGG corticotomy for the acceleration of canine retraction are scarce.

Alfawal et al, in 2018, compared the acceleration of canine retraction by Er:YAG laser-assisted corticotomy versus piezocision. They showed a significantly higher rate of canine retraction in the experimental side in both groups, which is in agreement with the results of our study. They used $12 \mathrm{~Hz}$ frequency and $3 \mathrm{~W}$ power while we used $30 \mathrm{~Hz}$ frequency and $3.5 \mathrm{~W}$ power. Also, they used flatbed scans for the casts while we used 3D scanners. ${ }^{46}$ Seifi et al, in 2012, used Er,Cr:YSGG laser irradiation without elevating a surgical soft tissue flap to enhance orthodontic tooth movement in rabbits. They showed a significantly higher amount of orthodontic tooth movement in the experimental group $(P<0.001) .{ }^{36}$ In 2016, Abbas et al studied the effect of corticotomyfacilitated orthodontics and piezocision on rapid canine retraction. They demonstrated that corticotomy caused a greater rate of canine movement than did piezocision at 4-time points. In their study, incisions and perforations were made using a piezotome, whereas the Er,Cr:YSGG laser was used for incision in our study. ${ }^{4}$

In the current study, the nickel-titanium closed-coil spring was preferred for canine retraction. Dixon et $\mathrm{al}^{47}$ and Von Fraunhofer et $\mathrm{al}^{48}$ reported the superiority of nickel-titanium closed-coil springs over the elastomeric chains. The nickel-titanium springs produce light, continuous force and also enable better oral hygiene compared with elastomeric chains. ${ }^{47}$ To benefit from the RAP (caused by bone damage), canine retraction was started immediately after surgery.

The current results showed that the rate of canine retraction in the control side was similar to the rate reported in the conventional technique, which is 0.5 to $1 \mathrm{~mm}$ per month (based on the patient's age and sex). ${ }^{4}$ The rate of canine retraction at 1 month was significantly higher in the laser side compared with the control side (about 2.5 times). This finding was consistent with the findings of Ren et $\mathrm{al}^{25}$ Wilcko et $\mathrm{al}^{49}$ Iino et $\mathrm{al},{ }^{50}$ and Aksakalli et $\mathrm{al}^{51}$ who reported faster tooth movement

Table 2. Intergroup and Intragroup Comparisons of the Mean GI Between the Control and Laser Groups

\begin{tabular}{llccc}
\hline \multirow{2}{*}{ Group } & Baseline & After 1 Month & Mean Difference \pm SE \\
\cline { 2 - 4 } & Mean \pm SD & Mean \pm SD & \\
\hline \multirow{2}{*}{ Gl } & Control side & $1.36 \pm 0.27$ & $1.34 \pm 0.23$ & $0.16 \pm 0.05$ \\
& Laser side & $1.50 \pm 0.37$ & $1.44 \pm 0.35$ & $0.061 \pm 0.05$ \\
\hline
\end{tabular}

Gl, gingival index; SE, standard error.

* Paired $t$ test; $* * t$ test. 
in the laser side than the control side. Greater tooth movement in the laser side can be explained by the RAP process and decreased the resistance of alveolar bone against tooth movement. The incision of alveolar bone can induce the expression of pro-inflammatory factors and increase the level of cytokines that enhance the activity of osteoclasts. As a result, bone remodeling occurs, which enhances tooth movement. ${ }^{46}$ This finding was consistent with the results of Frost and Wilcko et al, who showed that damage to the bone is directly related to the speed of tooth movement. ${ }^{31,49}$

Although the canine retraction rate was higher in the laser side than the control side, no adverse effects were seen in the anchorage unit. No significant difference was reported in the molar movement rate between the two sides. This finding was consistent with the results of Abbas et $\mathrm{al}^{4}$ and Alfawal et al. ${ }^{46}$

The use of $0.016 \times 0.022$-inch wire in the 0.022 -inch slot can lead to the uncontrolled tipping of the canine tooth. In the present study, the canine crown tipping in the laser side was more than that in the control side; this can be explained by the fact that an increase in RAP in the laser side increased the tooth movement, and more retraction occurred.

Contrary to the results of Levy and Bell ${ }^{4}$ and Yaffe et $\mathrm{al}^{52}$ who reported a reduction in the width of attached gingiva in their studies, we did not find any adverse effect on the attached gingiva after corticotomy, and the results of our study were consistent with the findings of Lino et

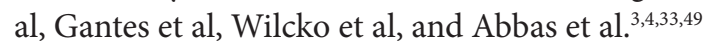

Preservation of attached gingiva in the present study may be due to the sub-marginal position of incision, avoiding heavy forces that would cause severe bone resorption and insisting on oral hygiene. Also, in the present study, no adverse effects were observed on the GI. ${ }^{44}$

The novelty of this clinical study was the use of the Er,Cr:YSGG laser with a $2780 \mathrm{~nm}$ wavelength for corticotomy to retract canines and the use of $3 \mathrm{D}$ scanners for the casts.

\section{Conclusion}

This randomized clinical trial indicated the optimal efficacy of lasercision corticotomy as a minimally invasive technique to increase the speed of canine retraction. This method has no adverse effects on gingival health or molar movement and is not painful for patients.

\section{Ethical Considerations}

The study was approved by the Ethics Committee of Hamadan University of Medical Sciences (IR.UMSHA. REC.1397.969) and registered in the Iranian Registry of Clinical Trials available at www.irct.ir (identifier: IRCT20120215009014N280).

\section{Conflict of Interests}

Each author of the present paper would like to declare that there is no conflict of interest. In addition, we affirm that we have no financial affiliation or involvement with any commercial organization with direct financial interest in the subject or materials discussed in this manuscript, nor do we have any such arrangements existed in the past three years.

\section{References}

1. Nimeri G, Kau CH, Abou-Kheir NS, Corona R. Acceleration of tooth movement during orthodontic treatment-a frontier in orthodontics. Prog Orthod. 2013;14:42. doi: 10.1186/2196-1042-14-42.

2. Fink DF, Smith RJ. The duration of orthodontic treatment. Am J Orthod Dentofacial Orthop. 1992;102(1):45-51. doi: 10.1016/0889-5406(92)70013-Z.

3. Fisher MA, Wenger RM, Hans MG. Pretreatment characteristics associated with orthodontic treatment duration. Am JOrthod Dentofacial Orthop. 2010;137(2):17886. doi: 10.1016/j.ajodo.2008.09.028.

4. Abbas NH, Sabet NE, Hassan IT. Evaluation of corticotomy-facilitated ortho dontics and piezocision in rapid canine retraction. Am J Orthod Dentofacial Orthop. 2016;149(4):473-80. doi: 10.1016/j.ajodo.2015.09.029.

5. Geiger AM, Gorelick L, Gwinnett AJ, Benson BJ. Reducing white spot lesions in orthodontic populations with fluoride rinsing. Am J Orthod Dentofacial Orthop. 1992;101(5):4037. doi: 10.1016/0889-5406(92)70112-N.

6. Bishara SE, Ostby AW, editors. White spot lesions: formation, prevention, and treatment .Semin Orthod. 2008;14(3):174-82. doi: 10.1053/j.sodo.2008.03.002.

7. Segal GR, Schiffman PH, Tuncay OC. Meta analysis of the treatment-related factors of external apical root resorption. Orthod Craniofac Res. 2004;7(2):71-8. doi: 10.1111/j.16016343.2004.00286.x.

8. Pandis N, Nasika M, Polychronopoulou A, Eliades T. External apical root resorption in patients treated with conventional and self-ligating brackets. Am J Orthod Dentofacial Orthop. 2008;134(5):646-51. doi: 10.1016/j. ajodo.2007.01.032.

9. Yi J, Xiao J, Li H, Li Y, Li X, Zhao Z. Effectiveness of adjunctive interventions for accelerating orthodontic tooth movement: a systematic review of systematic reviews. $J$ Oral Rehabil. 2017;44(8):636-54. doi: 10.1111/joor.12509.

10. Cruz DR, Kohara EK, Ribeiro MS, Wetter NU. Effects of low-intensity laser therapy on the orthodontic movement velocity of human teeth: A preliminary study. Lasers Surg Med. 2004;35(2):117-20. doi: 10.1002/lsm.20076.

11. Yamaguchi M, Hayashi M, Fujita S, Yoshida T, Utsunomiya $\mathrm{T}$, Yamamoto $\mathrm{H}$, et al. Low-energy laser irradiation facilitates the velocity of tooth movement and the expressions of matrix metalloproteinase-9, cathepsin $\mathrm{K}$, and alpha(v) beta(3) integrin in rats. Eur J Orthod. 2010;32(2):131-9. doi: 10.1093/ejo/cjp078.

12. Showkatbakhsh R, Jamilian A, Showkatbakhsh M. The effect of pulsed electromagnetic fields on the acceleration of tooth movement. World J Orthod. 2010;11(4):e52-6.

13. Hassan AH, Al-Fraidi AA, Al-Saeed SH. Corticotomyassisted orthodontic treatment: review. Open Dent J. 2010;4:159-64. doi: 10.2174/1874210601004010159.

14. Aboul-Ela SMB, El-Beialy AR, El-Sayed KMF, Selim 
EMN, El-Mangoury NH, Mostafa YA. Miniscrew implantsupported maxillary canine retraction with and without corticotomy-facilitated orthodontics. Am J Orthod Dentofacial Orthop. 2011;139(2):252-9. doi: 10.1016/j. ajodo.2009.04.028.

15. Liou EJ, Huang CS. Rapid canine retraction through distraction of the periodontal ligament. Am J Orthod Dentofacial Orthop. 1998;114(4):372-82. doi: 10.1016/ s0889-5406(98)70181-7.

16. Sayın S, Bengi AO, Gürton AU, Ortakoğlu K. Rapid canine distalization using distraction of the periodontal ligament: a preliminary clinical validation of the original technique. Angle Orthod. 2004;74(3):304-15. doi: 10.1043/0003-3219(2004)074<0304:RCDUDO>2.0.CO;2.

17. Işeri $H$, Kişnişci $R$, Bzizi $N$, Tüz $H$. Rapid canine retraction and orthodontic treatment with dentoalveolar distraction osteogenesis. Am J Orthod Dentofacial Orthop. 2005;127(5):533-41. doi: 10.1016/j.ajodo.2004.01.022.

18. Nishimura M, Chiba M, Ohashi T, Sato M, Shimizu Y, Igarashi $\mathrm{K}$, et al. Periodontal tissue activation by vibration: intermittent stimulation by resonance vibration accelerates experimental tooth movement in rats. Am J Orthod Dentofacial Orthop. 2008;133(4):572-83. doi: 10.1016/j. ajodo.2006.01.046.

19. Long H, Pyakurel U, Wang Y, Liao L, Zhou Y, Lai W. Interventions for accelerating orthodontic tooth movement: a systematic review. Angle Orthod. 2013;83(1):164-71. doi: 10.2319/031512-224.1.

20. Davidovitch Z. Tooth movement. Crit Rev Oral Biol Med. 1991;2(4):411-50. doi: 10.1177/10454411910020040101.

21. Davidovitch Z, Nicolay OF, Ngan PW, Shanfeld JL. Neurotransmitters, cytokines, and the control of alveolar bone remodeling in orthodontics. Dent Clin North Am. 1988;32(3):411-35.

22. Krishnan V, Davidovitch Z. Cellular, molecular, and tissue-level reactions to orthodontic force. Am J Orthod Dentofacial Orthop. 2006;129(4):469.e1-32. doi: 10.1016/j. ajodo.2005.10.007.

23. Kişnişci RŞ, Işeri H, Tüz HH, Altug AT. Dentoalveolar distraction osteogenesis for rapid orthodontic canine retraction. J Oral Maxillofac Surg. 2002;60(4):389-94. doi: 10.1053/joms.2002.31226.

24. Wilcko WM, Wilcko MT, Bouquot JE, Ferguson DJ. Rapid orthodontics with alveolar reshaping: two case reports of decrowding. Int J Periodontics Restorative Dent. 2001;21(1):9-19.

25. Ren A, Lv T, Kang N, Zhao B, Chen Y, Bai D. Rapid orthodontic tooth movement aided by alveolar surgery in beagles. Am J Orthod Dentofacial Orthop. 2007;131(2):160. e1-10. doi: 10.1016/j.ajodo.2006.05.029.

26. Dibart S, Surmenian J, Sebaoun JD, Montesani L. Rapid treatment of Class II malocclusion with piezocision: two case reports. Int $J$ Periodontics Restorative Dent. 2010;30(5):487-93.

27. Lee W, Karapetyan G, Moats R, Yamashita DD, Moon HB, Ferguson DJ, et al. Corticotomy- /osteotomy-assisted tooth movement microCTs differ. J Dent Res. 2008;87(9):861-7. doi: $10.1177 / 154405910808700904$

28. Köle H. Surgical operations on the alveolar ridge to correct occlusal abnormalities. Oral Surg Oral Med Oral Pathol. 1959;12(5):515-29. doi: 10.1016/0030-4220(59)90153-7.
29. Patterson BM, Dalci O, Darendeliler MA, Papadopoulou AK. Corticotomies and orthodontic tooth movement: a systematic review. J Oral Maxill Surg. 2016;74(3):453-73.

30. Cano J, Campo J, Bonilla E, Colmenero C. Corticotomyassisted orthodontics. J Clin Exp Dent. 2012;4(1):e54-9. doi: $10.4317 /$ jced.50642.

31. Frost $\mathrm{H}$. The regional accelerated phenomenon. Orthop Clin N Am. 1981;12(725):6.

32. Kim SJ, Moon SU, Kang SG, Park YG. Effects of low-level laser therapy after Corticision on tooth movement and paradental remodeling. Lasers in Surgery and Medicine: The Official Journal of the American Society for Laser Medicine and Surgery. 2009;41(7):524-33.

33. Gantes B, Rathbun E, Anholm M. Effects on the periodontium following corticotomy-facilitated orthodontics. Case reports. J Periodontol. 1990;61(4):2348. doi: 10.1902/jop.1990.61.4.234.

34. Wilcko W, Wilcko M, Bouquot J, Ferguson D. Accelerated orthodontics with alveolar reshaping. J Ortho Practice. 2000;10(1):63-70.

35. Kamal AT, Malik DS, Fida M, Sukhia RH. Does periodontally accelerated osteogenic orthodontics improve orthodontic treatment outcome? A systematic review and meta-analysis. Int Orthod. 2019;17(2):193-201. doi: 10.1016/j.ortho.2019.03.006.

36. Seifi M, Younessian F, Ameli N. The innovated laser assisted flapless corticotomy to enhance orthodontic tooth movement. J Lasers Med Sci. 2012;3(1):20-25.

37. Wang X, Ishizaki NT, Suzuki N, Kimura Y, Matsumoto K. Morphological changes of bovine mandibular bone irradiated by Er,Cr:YSGG laser: an in vitro study. J Clin Laser Med Surg. 2002;20(5):245-50. doi: 10.1089/10445470260420740.

38. Wang $\mathrm{X}$, Zhang $\mathrm{C}$, Matsumoto $\mathrm{K}$. In vivo study of the healing processes that occur in the jaws of rabbits following perforation by an Er,Cr:YSGG laser. Lasers Med Sci. 2005;20(1):21-7. doi: 10.1007/s10103-005-0329-y.

39. Kimura Y, Yu DG, Fujita A, Yamashita A, Murakami Y, Matsumoto K. Effects of erbium,chromium:YSGG irradiation on canine mandibular bone. J Periodontol. 2001;72(9):1178-82. doi: 10.1902/jop.2000.72.9.1178.

40. Salman LH, Ali FA. Acceleration of canine movement by laser assisted flapless corticotomy: An innovative approach in clinical orthodontics. J Bagh College Dentistry. 2014;26(3):133-7. doi: 10.12816/0015238.

41. Savard B. Alveolar corticotomies by lasercision: a minimally invasive procedure to accelerate orthodontic treatments in adult patients. J Dentofacial Anom Orthod. 2016;19(4):405. doi: 10.1051/odfen/2016025.

42. Cassetta M, Altieri F, Pandolfi S, Giansanti M. The combined use of computer-guided, minimally invasive, flapless corticotomy and clear aligners as a novel approach to moderate crowding: a case report. Korean J Orthod. 2017;47(2):130-41. doi: 10.4041/kjod.2017.47.2.130.

43. Cassetta M, Giansanti M, Di Mambro A, Calasso S, Barbato E. Minimally invasive corticotomy in orthodontics using a three-dimensional printed CAD/CAM surgical guide. Int J Oral Maxillofac Surg. 2016;45(9):1059-64. doi: 10.1016/j. ijom.2016.04.017.

44. Löe $\mathrm{H}$. The gingival index, the plaque index and the retention index systems. J Periodontol. 1967;38(6):610-6. 
doi: 10.1902/jop.1967.38.6.610.

45. Hoggan BR, Sadowsky C. The use of palatal rugae for the assessment of anteroposterior tooth movements. Am J Orthod Dentofacial Orthop. 2001;119(5):482-8. doi: 10.1067/mod.2001.113001.

46. Alfawal AMH, Hajeer MY, Ajaj MA, Hamadah O, Brad B. Evaluation of piezocision and laser-assisted flapless corticotomy in the acceleration of canine retraction: a randomized controlled trial. Head Face Med. 2018;14(1):4. doi: 10.1186/s13005-018-0161-9.

47. Dixon V, Read MJF, O'Brien KD, Worthington HV, Mandall NA. A randomized clinical trial to compare three methods of orthodontic space closure. J Orthod. 2002;29(1):31-6. doi: 10.1093/ortho/29.1.31.

48. Von Fraunhofer J, Bonds P, Johnson B. Force generation by orthodontic coil springs. Angle Orthod. 1993;63(2):145-8.

49. Wilcko MT, Wilcko WM, Bissada NF. An evidence- based analysis of periodontally accelerated orthodontic and osteogenic techniques: a synthesis of scientific perspectives. Semin Orthod. 2008;14(4):305-316. doi: 10.1053/j.sodo.2008.07.007.

50. Iino S, Sakoda S, Ito G, Nishimori T, Ikeda T, Miyawaki S. Acceleration of orthodontic tooth movement by alveolar corticotomy in the dog. Am J Orthod Dentofac. 2007;131(4):448. e1- e8.

51. Aksakalli S, Calik B, Kara B, Ezirganli S. Accelerated tooth movement with piezocision and its periodontal-transversal effects in patients with Class II malocclusion. Angle Orthod. 2016;86(1):59-65. doi: 10.2319/012215-49.1.

52. Yaffe A, Fine N, Binderman I. Regional accelerated phenomenon in the mandible following mucoperiosteal flap surgery. J Periodontol. 1994;65(1):79-83. doi: 10.1902/ jop.1994.65.1.79. 